\title{
Synthesis, characterization, and in vitro evaluation of novel polymer-coated magnetic nanoparticles for controlled delivery of doxorubicin
}

This article was published in the following Dove Press journal:

Nanotechnology, Science and Applications

3 February 2012

Number of times this article has been viewed

\begin{abstract}
Abolfazl Akbarzadeh'
Nosratollah Zarghami ${ }^{2}$

Haleh Mikaeili ${ }^{3}$

Davoud Asgari ${ }^{4}$

Amir Mohammad Goganian ${ }^{5}$

Hanie Khaksar Khiabani ${ }^{5}$

Mohammad Samiei ${ }^{6}$

Soodabeh Davaran ${ }^{3}$

'Department of Medicinal Chemistry, Tabriz University of Medical Sciences, ${ }^{2}$ Department of Clinical Biochemistry and Laboratory Medicine, Division of Medical Biotechnology, Faculty of Medicine, Tabriz University of Medical Sciences, ${ }^{3}$ Tuberculosis and Lung Disease Research Center, Tabriz University of Medical Sciences, ${ }^{4}$ Research Center for Pharmaceutical Nanotechnology, Tabriz University of Medical Sciences, ${ }^{5}$ Department of Organic Chemistry, Faculty of Chemistry, University of Tabriz, ${ }^{6}$ Faculty of Dentistry, Tabriz University of Medical Sciences, Tabriz, Iran
\end{abstract}

Correspondence: Soodabeh Davaran

Tuberculosis and Lung Disease Research Center, Tabriz University of Medical

Sciences, Tabriz, Iran

Tel +98 4I I 337225

Fax +98 4I I334 4798

Email davaran@tbzmed.ac.ir

\begin{abstract}
Poly (N-isopropylacrylamide-methyl methacrylic acid, PNIPAAm-MAA)-grafted magnetic nanoparticles were synthesized using silane-coated magnetic nanoparticles as a template for radical polymerization of $\mathrm{N}$-isopropylacrylamide and methacrylic acid. Properties of these nanoparticles, such as size, drug-loading efficiency, and drug release kinetics, were evaluated in vitro for targeted and controlled drug delivery. The resulting nanoparticles had a diameter of $100 \mathrm{~nm}$ and a doxorubicin-loading efficiency of $75 \%$, significantly higher doxorubicin release at $40^{\circ} \mathrm{C}$ compared with $37^{\circ} \mathrm{C}$, and $\mathrm{pH} 5.8$ compared with $\mathrm{pH} 7.4$, demonstrating their temperature and $\mathrm{pH}$ sensitivity, respectively. In addition, the particles were characterized by $\mathrm{X}$-ray powder diffraction, scanning electron microscopy, Fourier transform infrared spectroscopy, and vibrating sample magnetometry. In vitro cytotoxicity testing showed that the PNIPAAmMAA-coated magnetic nanoparticles had no cytotoxicity and were biocompatible, indicating their potential for biomedical application.
\end{abstract}

Keywords: magnetic nanoparticles, drug loading, doxorubicin release, biocompatibility

\section{Introduction}

Magnetic nanoparticles are a major class of nanoscale materials with the potential to revolutionize current clinical diagnostic and therapeutic techniques. ${ }^{1}$ Due to their unique physical properties and ability to function at the cellular and molecular level of biological interactions, magnetic nanoparticles are being actively investigated as the next generation of magnetic resonance imaging contrast agents ${ }^{2}$ and as carriers for targeted drug delivery. ${ }^{3,4}$ Although early research in the field can be dated back several decades, the recent surge of interest in nanotechnology has significantly expanded the breadth and depth of research into magnetic nanoparticles. With a wide range of applications in the detection, diagnosis, and treatment of illnesses, such as cancer, ${ }^{5}$ cardiovascular disease, ${ }^{6}$ and neurological disease, ${ }^{7-10}$ magnetic nanoparticles may soon play a significant role in meeting the health care needs of tomorrow (Figure 1).

As therapeutic tools, magnetic nanoparticles have been evaluated extensively for targeted delivery of pharmaceuticals through magnetic drug targeting, ${ }^{11-16}$ and by active targeting through attachment of high affinity ligands. ${ }^{17-19}$ With the ability to utilize magnetic attraction and/or specific targeting of disease biomarkers, magnetic nanoparticles offer an attractive means of remotely directing therapeutic agents specifically to a disease site, while simultaneously reducing dosage and the deleterious side effects associated with nonspecific uptake of cytotoxic drugs by healthy tissue.

Also referred to as magnetic targeted carriers, colloidal iron oxide particles in early clinical trials have demonstrated some degree of success with the technique 


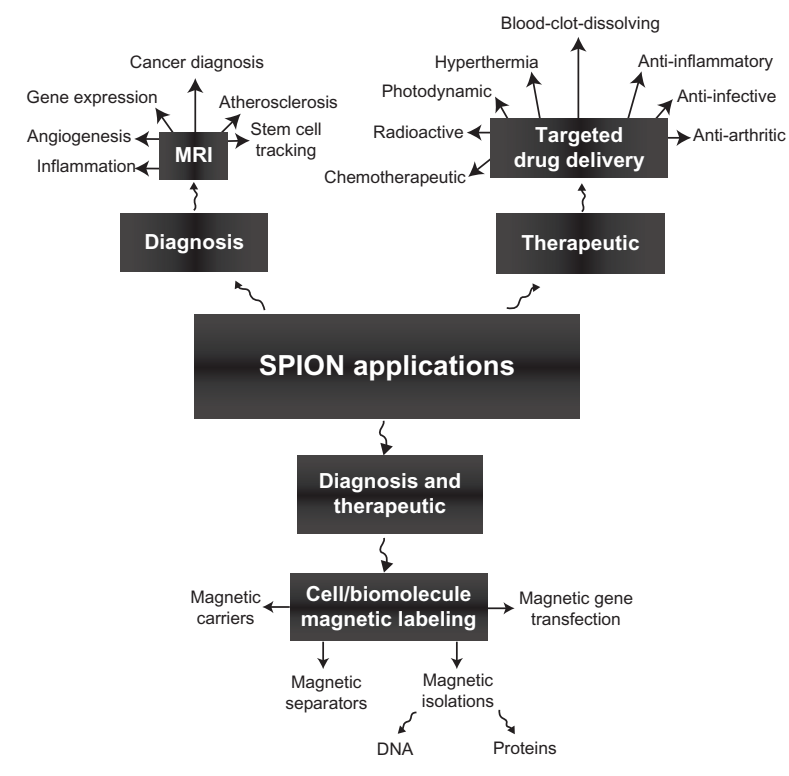

Figure I Applications of superparamagnetic iron oxide nanoparticles. Abbreviation: SPION, superparamagnetic iron oxide nanoparticle.

and shown satisfactory tolerability in patients..$^{20-22}$ Although not yet capable of reaching levels of safety and efficacy for regulatory approval, preclinical studies indicate that some of the shortcomings of magnetic drug targeting technology, such as poor penetration depth and diffusion of the released drug from the disease site, can be overcome by improvements in magnetic targeted carrier design. ${ }^{23,24}$

Furthermore, the use of magnetic nanoparticles as carriers in multifunctional nanoplatforms as a means of real-time monitoring of drug delivery is an area of intense interest. ${ }^{25,26}$ A significant challenge associated with the application of these magnetic nanoparticle systems is their behavior in vivo. The efficacy of many of these systems is often compromised due to recognition and clearance by the reticuloendothelial system prior to reaching the target tissue, as well as by an inability to overcome biological barriers, such as the vascular endothelium or the blood-brain barrier. The fate of these magnetic nanoparticles upon intravenous administration is highly dependent on their size, morphology, charge, and surface chemistry.

The physicochemical properties of nanoparticles directly affect their subsequent pharmacokinetics and biodistribution. ${ }^{27}$ To increase the effectiveness of magnetic nanoparticles, several techniques, including reducing size and grafting nonfouling polymers, have been used to improve their "stealthiness" and increase their blood circulation time to maximize the likelihood of reaching targeted tissues. ${ }^{28,29}$ The major disadvantage of most chemotherapeutic approaches to cancer treatment is that most are nonspecific.
Therapeutic (generally cytotoxic) drugs are administered intravenously, leading to general systemic distribution. ${ }^{30-33}$

The nonspecific nature of this technique results in the well known side effects of chemotherapy because the cytotoxic drug attacks normal healthy cells in addition to its primary target, ie, tumor cells. ${ }^{34}{ }^{41}$ To overcome this great disadvantage, magnetic nanoparticles can be used to treat tumors in three different ways: specific antibodies can be conjugated to the magnetic nanoparticles to bind selectively to related receptors and inhibit tumor growth; targeted magnetic nanoparticles can be used for hyperthermia for tumor therapy; and drugs can be loaded into magnetic nanoparticles for targeted therapy. ${ }^{42-45}$ Targeted delivery of antitumor agents adsorbed on the surface of magnetic nanoparticles is a promising alternative to conventional chemotherapy (Figure 2).

Particles loaded with the drug are concentrated at the target site with the aid of an external magnet. The drugs are then released in the desired area. ${ }^{46}$ Magnetic particles smaller than $4 \mu \mathrm{m}$ are eliminated by cells of the reticuloendothelial system, mainly in the liver $(60 \%-90 \%)$ and spleen $(3 \%-10 \%)$. Particles larger than $200 \mathrm{~nm}$ are usually filtered to the spleen, the cutoff point of which extends up to $250 \mathrm{~nm}$, while particles up to $100 \mathrm{~nm}$ are mainly phagocytosed by liver cells.

In general, the larger the particles are, the shorter their plasma half-life. ${ }^{47}$ Functionalization of magnetic nanoparticles with amino groups, silica, polymers, various surfactants, or other organic compounds is usually performed in order to achieve better physical and chemical properties. Moreover, the core/shell structure of magnetic nanoparticles has the advantages of good dispersion, high stability against oxidation, and an appreciable amount of drug can be loaded into the polymer shell. Furthermore, lots of functional groups from polymers on the surface can be used
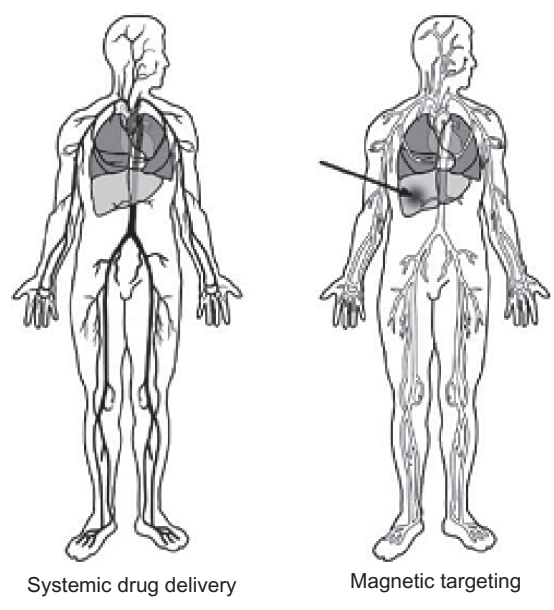

Figure 2 Concept of magnetic drug targeting. 
for further functionalization to obtain various properties. ${ }^{48}$ It is preferable that magnetic nanoparticles retain sufficient hydrophilicity and, with coating, do not exceed $100 \mathrm{~nm}$ in size to avoid rapid clearance by the reticuloendothelial system. ${ }^{49}$ It has been found that surface functionalization also plays a key role in nanoparticle toxicity.

In this research we investigated the in vitro characteristics of our nanoparticles for drug delivery application..$^{50}$ Of these temperature-sensitive polymer-coated magnetic nanoparticles, poly-N-isopropylacrylamide (PNIPAAm)-coated magnetic nanoparticles are of particular interest because of their stimuli (temperature) responsiveness and enhanced drug-loading ability. These characteristics are due to their large inner volume, amphiphilicity, capacity for manipulation of permeability, and response to an external temperature stimulus with an on-off mechanism. However, one potential problem with using PNIPAAm as a polymer coat is that its lower critical solution temperature, ie, the temperature at which a phase transition occurs, is below body temperature $\left(32^{\circ} \mathrm{C}\right)$. To increase the lower critical solution temperature of PNIPAAm above body temperature, it has been copolymerized with different monomers. ${ }^{51,52}$

Two synthetic steps were used to manufacture magnetic nanoparticles coated with PNIPAAm and methacrylic acid (MAA) ${ }^{53}$ First, magnetic nanoparticles were covalently bound with vinyltriethoxysilane, a silane coupling agent, to produce a template site for radical polymerization. NIPAAm and MAA were then polymerized on the silicon layer around the magnetic nanoparticles via methylene-bis-acrylamide and ammonium persulfate as a cross-linking agent and an initiator, respectively. The resultant particles were characterized by X-ray powder diffraction, scanning electron microscopy, Fourier transform infrared spectroscopy, and vibrating sample magnetometry. The in vitro cytotoxicity test for the PNIPAAm-MAA-coated magnetic nanoparticles was analyzed. The drug-release behavior of doxorubicin (an anticancer drug model) from the nanoparticles at various $\mathrm{pH}$ levels and at different temperatures below and at the lower critical solution temperature was also analyzed. Being able to monitor the location of drug-loaded nanoparticles after administration would be a considerable advantage in situations such as cancer therapy, in which drugs have serious side effects in healthy tissue. ${ }^{1,54}$

\section{Materials and methods \\ Materials}

Ferric chloride hexahydrate $\left(\mathrm{FeCl}_{3} \cdot 6 \mathrm{H}_{2} \mathrm{O}\right)$, ferrous chloride tetrahydrate $\left(\mathrm{FeCl}_{2} \cdot 4 \mathrm{H}_{2} \mathrm{O}\right)$, ammonium hydroxide $(25 \mathrm{wt} \%$, and other chemicals of analytical grade were purchased from Fluka (Buchs, Switzerland). 1,4 dioxan, ammonium persulfate, AIBN (2 azobisisobutyronitrile), MAA, NIPAAm, methylene-bis-acrylamide (BIS), vinyltriethoxysilane, acetic acid, and ethanol were purchased from Sigma-Aldrich (St Louis, MO) and used as received. Doxorubicin hydrochloride was purchased from Sigma-Aldrich. X-ray powder diffraction using a Rigaku D/MAX-2400 X-ray diffractometer with Ni-filtered $\mathrm{Cu} \mathrm{K} \alpha$ radiation and scanning electron microscopy measurements were conducted using a VEGA/TESCAN Drug-loading capacity and release behavior were determined using an ultraviolet 2550 spectrometer (Shimadzu, Japan, Tokyo). The infrared spectra of copolymers were recorded on a Perkin Elmer 983 infrared spectrophotometer (Perkin Elmer, Boston, MA) at room temperature. Magnetic properties were measured on a VSM/AGFM (Meghnatis Daghigh Kavir Co, Iran) vibrating sample magnetometer at room temperature.

\section{Synthesis of superparamagnetic magnetite nanoparticles}

Superparamagnetic magnetite $\left(\mathrm{Fe}_{3} \mathrm{O}_{4}\right)$ nanoparticles were prepared using an improved chemical coprecipitation method . According to this method, $3.1736 \mathrm{~g}$ of FeCl $2 \cdot 4 \mathrm{H}_{2} \mathrm{O}(0.016 \mathrm{~mol})$ and $7.5684 \mathrm{~g}$ of $\mathrm{FeCl}_{3} \cdot 6 \mathrm{H}_{2} \mathrm{O}(0.028 \mathrm{~mol})$ were dissolved in $320 \mathrm{~mL}$ of deionized water, such that $\mathrm{Fe}^{2+} / \mathrm{Fe}^{3+}=1 / 1.75$. The mixed solution was stirred under $\mathrm{N}_{2}$ at $80^{\circ} \mathrm{C}$ for one hour. Then, $40 \mathrm{~mL}$ of $\mathrm{NH}_{3} \cdot \mathrm{H}_{2} \mathrm{O}$ was injected into the mixture rapidly, stirred under $\mathrm{N}_{2}$ for another hour, and cooled to room temperature. The precipitated particles were washed five times with hot water and separated by magnetic decantation (Figure 3). Finally, the magnetic nanoparticles were dried under vacuum at $70^{\circ} \mathrm{C} .{ }^{55}$

\section{Preparation of vinyltriethoxysilane-coated magnetic nanoparticles}

The magnetic nanoparticles were coated with vinyltriethoxysilane via acid catalyst hydrolysis, followed by electrophilic substitution of ferrous oxide on the surface as shown in our previous study. In brief, $0.49 \mathrm{~mL}$ of vinyltriethoxysilane was hydrolyzed

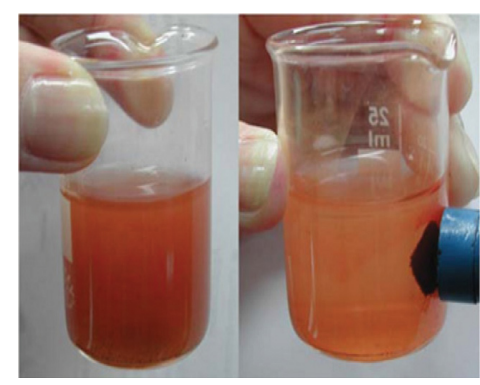

Figure 3 Magnetite-hexane suspension attached to a magnet. 
using $3 \mathrm{~mL}$ of acetic acid in the presence of water and ethanol (1:100 vol/vol). A measured quantity $(0.075 \mathrm{~g})$ of magnetic nanoparticles was then dispersed by sonication at $100 \mathrm{~W}$ for 30 minutes in this solution. After 18 hours of vigorous mechanical stirring at room temperature $\left(22^{\circ} \mathrm{C}-25^{\circ} \mathrm{C}\right)$, vinyltriethoxysilane-coated magnetic nanoparticles were obtained, washed with a mixture of water and ethanol (1:100 vol/vol) and collected using an external magnet. The particles were dispersed in water before the next step.

\section{Immobilization of PNIPAAm-MAA on magnetic nanoparticles}

Vinyltriethoxysilane-coated magnetic nanoparticles were used as a template to polymerize PNIPAAm-MAA in 1,4 dioxan. BIS was used as a cross-linking agent. In brief, $0.03 \mathrm{~g}$ of vinyltriethoxysilane-coated magnetic nanoparticles, $0.15 \mathrm{~g}$ of NIPAAm, $0.013 \mathrm{~g}$ of MAA, and $0.0135 \mathrm{~g}$ of BIS were sonicated in $100 \mathrm{~mL}$ of cold water for 45 minutes. Then, $0.08 \mathrm{~g}$ of ammonium persulfate was added to the solution, and the reaction was carried out at room temperature under $\mathrm{N}_{2}$ gas for 5 hours. The product was purified several times with deionized water by using a magnet to collect only the PNIPAAm-MAAcoated magnetic nanoparticles. PNIPAAm-coated magnetic nanoparticles were also formulated using the same synthesis process as for PNIPAAm-MAA-coated magnetic nanoparticles, but without addition of MAA monomers (Figure 4). ${ }^{56}$

\section{Synthesis of hybrid nanoparticles}

Doxorubicin was used as a model drug in our drug-loading and drug-release experiments. In brief, $5 \mathrm{mg}$ of freeze-dried PNIPAAm-MAA-coated magnetic nanoparticles and $2.5 \mathrm{mg}$ of doxorubicin were dispersed in $30 \mathrm{~mL}$ of phosphate buffer solution. The solution was stirred at $5^{\circ} \mathrm{C}$ for 3 days.
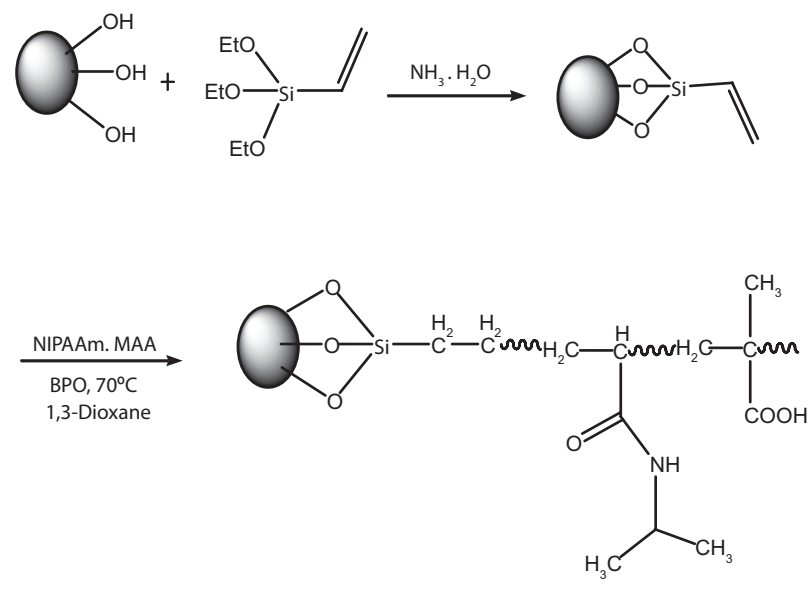

Figure 4 Chemical modification of $\mathrm{Fe}_{3} \mathrm{O}_{4}$ surface by grafting polymerization. Abbreviations: NIPAAm, N-isopropylacrylamide; MAA, methyl methacrylic acid.
The doxorubicin-loaded PNIPAAm-MAA-coated magnetic nanoparticles were separated from the solution using an external magnet. The solution was then analyzed using an ultraviolet-visible spectrofluorometer (Shimadzu) to determine the amount of nonencapsulated doxorubicin $\left(\lambda_{\mathrm{ex}} 470 \mathrm{~nm}\right.$ and $\left.\lambda_{\text {em }} 585 \mathrm{~nm}\right)$. This value was then compared with the total amount of doxorubicin added to determine the doxorubicinloading efficiency of the nanoparticles. ${ }^{57}$

\section{In vitro drug-release kinetics}

To study drug release, four different sets of experiments were performed. These included two temperatures $\left(40^{\circ} \mathrm{C}\right.$ and $37^{\circ} \mathrm{C}$ ) and two $\mathrm{pH}$ levels (5.8 and 7.4). In each drug-release experiment, $3.0 \mathrm{mg}$ of the drug carrier bonded with smart polymer was sealed in a $30 \mathrm{~mL}$ of $\mathrm{Na}_{2} \mathrm{HPO}_{4}-\mathrm{NaH}_{2} \mathrm{PO}_{4}$ buffer solution at a $\mathrm{pH}$ of 5.8 or 7.4 . The test tube with a closer was placed in a water bath maintained at $40^{\circ} \mathrm{C}$ up to the lower critical solution temperature or $37^{\circ} \mathrm{C}$ (higher than the lower critical solution temperature). The release medium (about $3 \mathrm{~mL}$ ) was withdrawn at predetermined time intervals $(1,2$, $3,4,5,6,7,8,9,12,24,36,48,60,80,100,130,160,190$, and 220 hours). Thereafter, the samples were analyzed using an ultraviolet-visible spectrometer (Shimadzu) to determine the amount of doxorubicin released $\left(\lambda_{\mathrm{ex}} 470 \mathrm{~nm}\right.$ and $\lambda_{\mathrm{em}}$ $585 \mathrm{~nm}$ for doxorubicin measurement). ${ }^{58,59}$

\section{Cell culture}

In vitro cytotoxicity and cell culture study

An A549 lung cancer cell line (kindly donated by the Pharmaceutical Nanotechnology Research Center, Tabriz University of Medical Sciences, Tabriz, Iran) were cultured in RPMI 1640 (Gibco, Invitrogen, Paisley, UK) supplemented with 10\% heat-inactivated fetal bovine serum (Gibco), $2 \mathrm{mg} / \mathrm{mL}$ sodium bicarbonate, $0.05 \mathrm{mg} / \mathrm{mL}$ penicillin $\mathrm{G}$ (Serva Co, Tübingen, Germany), and $0.08 \mathrm{mg} / \mathrm{mL}$ streptomycin (Merck Co, Germany), and incubated at $37^{\circ} \mathrm{C}$ with humidified air containing $5 \% \mathrm{CO}_{2}$. After culturing a sufficient amount of cells, the cytotoxic effect of PNIPAAm-MAA-coated magnetic nanoparticles was studied by MTT assay at 24, 48 and 72 hours. ${ }^{60}$ Briefly, 1000 cells/well were cultivated in a 96-well plate (Figure 5). After 24 hours of incubation at $37^{\circ} \mathrm{C}$ in a humidified atmosphere containing $5 \% \mathrm{CO}_{2}$, the cells were treated with serial concentrations of doxorubicin-loaded PNIPAAm-MAA-coated magnetic nanoparticles $(0 \mathrm{mg} / \mathrm{mL}$ to $0.57 \mathrm{mg} / \mathrm{mL}$ ) for 24,48 and 72 hours in a quadruplicate manner. Control cells received $0 \mathrm{mg} / \mathrm{mL}$ extract $+200 \mu \mathrm{L}$ of culture medium containing 10\% dimethylsulfoxide. After incubation, the medium in all wells was exchanged with fresh 


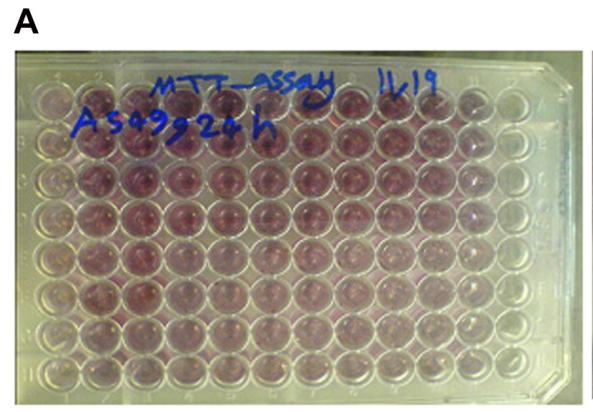

\section{B}

C
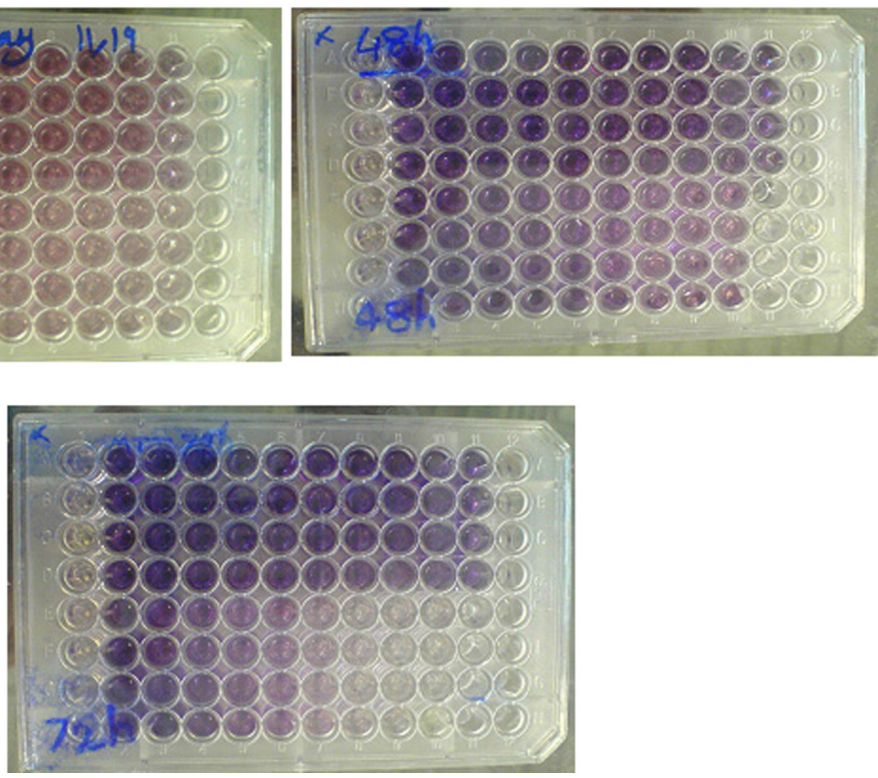

Figure 5 Cytotoxic effect of PNIPAAm-MAA-coated magnetic nanoparticles on A549 lung cancer cell line after 24 hours (A), 48 hours (B), and 72 hours (C) of exposure. Abbreviations: PNIPAAm, poly (N-isopropylacrylamide); MAA, methyl methacrylic acid.

medium, and the cells were left for 24 hours in an incubator. The medium in all the wells was then removed carefully, and $50 \mu \mathrm{L}$ of $2 \mathrm{mg} / \mathrm{mL}$ MTT dissolved in phosphate buffer solution was added to each well and the plate was covered with aluminum foil and incubated for 4.5 hours. After removing the contents of the wells, $200 \mu \mathrm{L}$ of pure dimethylsulfoxide was added to the wells. Then, $25 \mu \mathrm{L}$ of Sorensen's glycine buffer was added, and the absorbance of each well was immediately read at $570 \mathrm{~nm}$ using an EL $\times 800$ microplate absorbance reader (Bio-Tek Instruments, Winooksi, VT) with a reference wavelength of $630 \mathrm{~nm}$ (Figure 5). ${ }^{61}$

\section{Cell treatment}

After determination of the $\mathrm{IC}_{50}, 1 \times 10^{6}$ cells were treated with serial concentrations of doxorubicin-loaded PNIPAAmMAA-coated magnetic nanoparticles $(0.028,0.057,0.114$, $0.142,0.171$, and $0.199 \mathrm{mg} / \mathrm{mL}$ ). For control cells, the same volume of $10 \%$ dimethylsulfoxide without the doxorubicinloaded PNIPAAm-MAA-coated magnetic nanoparticles was added to the flask containing control cells. The culture flasks were then incubated for 24 hours at $37^{\circ} \mathrm{C}$ in a humidified atmosphere containing $5 \% \mathrm{CO}_{2}$ ( Figure 6).

\section{Characterization}

The infrared spectra were recorded using a Fourier transform infrared spectrophotometer (FT-IR, Nicolet NEXUS 670; ThermoScientific, Waltham, MA), and the sample and $\mathrm{KBr}$ were pressed to form a tablet. The magnetization curves of the samples were measured using vibrating sample magnetometry
(Meghnatis Daghigh Kavir Co) at room temperature. Powder X-ray diffraction (Rigaku D/MAX-2400 X-ray diffractometer with $\mathrm{Ni}$-filtered $\mathrm{Cu} \mathrm{K} \alpha$ radiation) was used to investigate the crystal structure of the magnetic nanoparticles. The infrared spectra of the copolymers were recorded on a Perkin Elmer 983 infrared spectrometer (Perkin Elmer) at room temperature. The size and shape of the nanoparticles were determined using a scanning electron microscope (VEGA/ TESCAN), whereby a sample was dispersed in ethanol and a small drop was spread onto a 400 mesh copper grid.

\section{Results}

\section{Synthesis of PNIPAAm-MAA-coated $\mathrm{Fe}_{3} \mathrm{O}_{4}$ nanoparticles}

The processes for synthesis of PNIPAAm-MAA-coated $\mathrm{Fe}_{3} \mathrm{O}_{4}$ nanoparticles and the loading of doxorubicin onto them are shown in Figure 4. The $\mathrm{Fe}_{3} \mathrm{O}_{4}$ nanoparticles were prepared by chemical coprecipitation of $\mathrm{Fe}^{2+}$ and $\mathrm{Fe}^{3+}$ ions under alkaline conditions. The concentration ratio of $\mathrm{Fe}^{2+} / \mathrm{Fe}^{3+}$ was selected to be $1: 1.8$ rather than the stoichiometric ratio of $1: 2$, because $\mathrm{Fe}^{2+}$ is prone to oxidation and becoming $\mathrm{Fe}^{3+}$ in solution. $\mathrm{Fe}_{3} \mathrm{O}_{4}$ nanoparticles prepared by the coprecipitation method have a number of hydroxyl groups on the surface from being in contact with the aqueous phase. Vinyltriethoxysilane-modified $\mathrm{Fe}_{3} \mathrm{O}_{4}$ nanoparticles were achieved by the reaction between vinyltriethoxysilane and the hydroxyl groups on the surface of magnetite. Two reactions were involved in the process. 
A

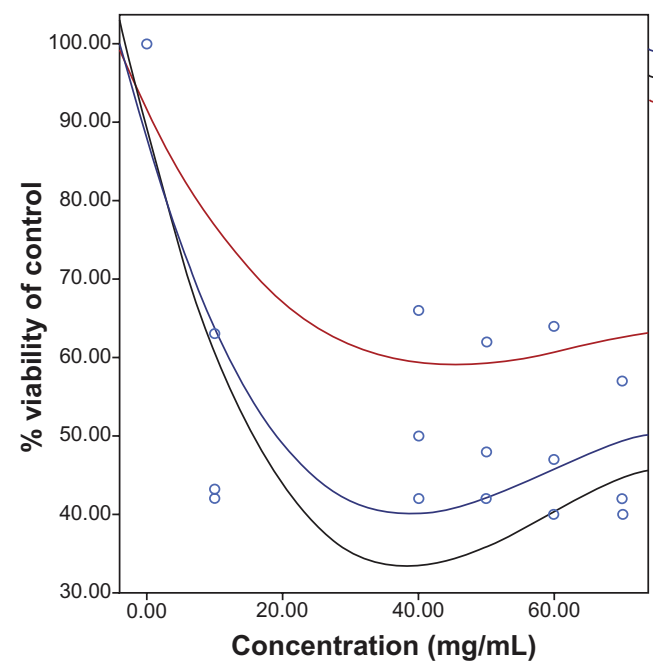

B

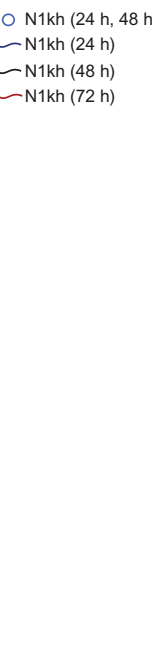

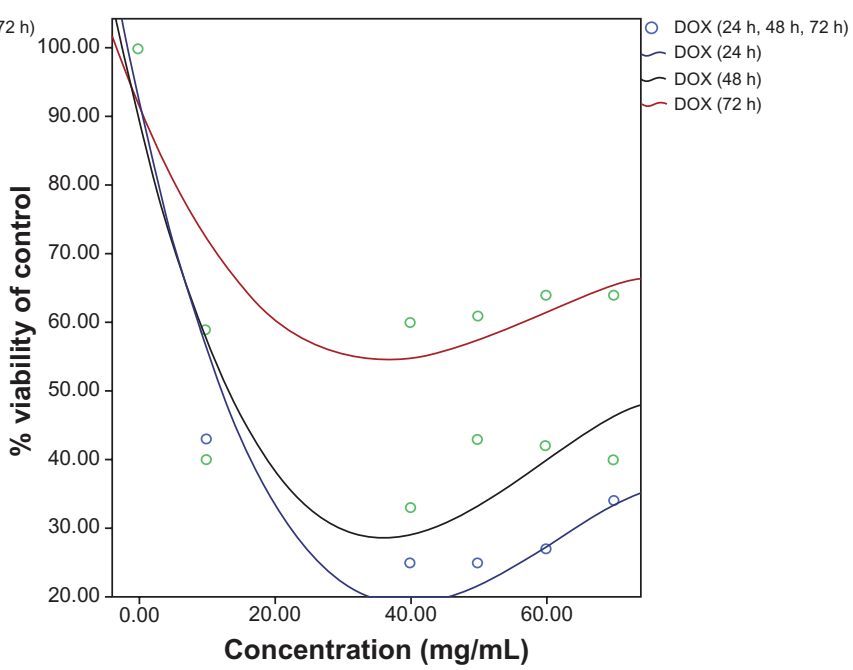

Figure $6 \mathrm{IC}_{50}$ of $(\mathbf{A})$ doxorubicin-loaded PNIPAAm-MAA-coated magnetic nanoparticles and (B) pure doxorubicin on A549 tumor cell line after 24,48 , and 72 hours of treatment.

Abbreviations: DOX, doxorubicin; PNIPAAm, poly (N-isopropylacrylamide); MAA, methyl methacrylic acid.

First, the vinyltriethoxysilane was hydrolyzed to highly reactive silanol species in the solution phase under alkaline conditions. Their condensation with surface free $-\mathrm{OH}$ groups of magnetite to form stable $\mathrm{Fe}-\mathrm{O}-\mathrm{Si}$ bonds then takes place. Oligomerization of the silanols in solution also occurs as a competing reaction, with their covalent binding to the surface. Surface-grafted polymerization by NIPAAm and MAA also involves two reactions which take place simultaneously. Graft polymerization occurs on the surface of the vinyltriethoxysilane-modified $\mathrm{Fe}_{3} \mathrm{O}_{4}$ nanoparticles, while random polymerization takes place in the solution. In order to decrease random polymerization, the following strategies were adopted. After azobisisobutyronitrile was dissolved in the modified nanoparticle-suspended solution, the solution was kept overnight for the nanoparticles to absorb as much azobisisobutyronitrile as possible onto the surface. An optimal concentration of initiator was selected, BIS was used as cross-linking agent, and the monomers were added dropwise in the reaction. The unreacted oligomers were separated by magnetic decantation after the reaction.
A

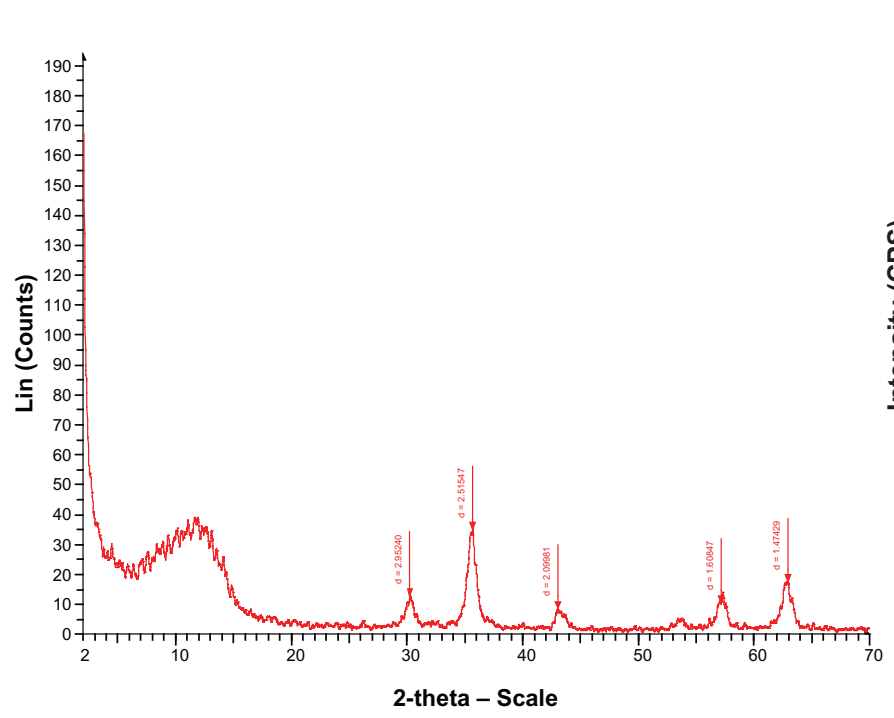

B

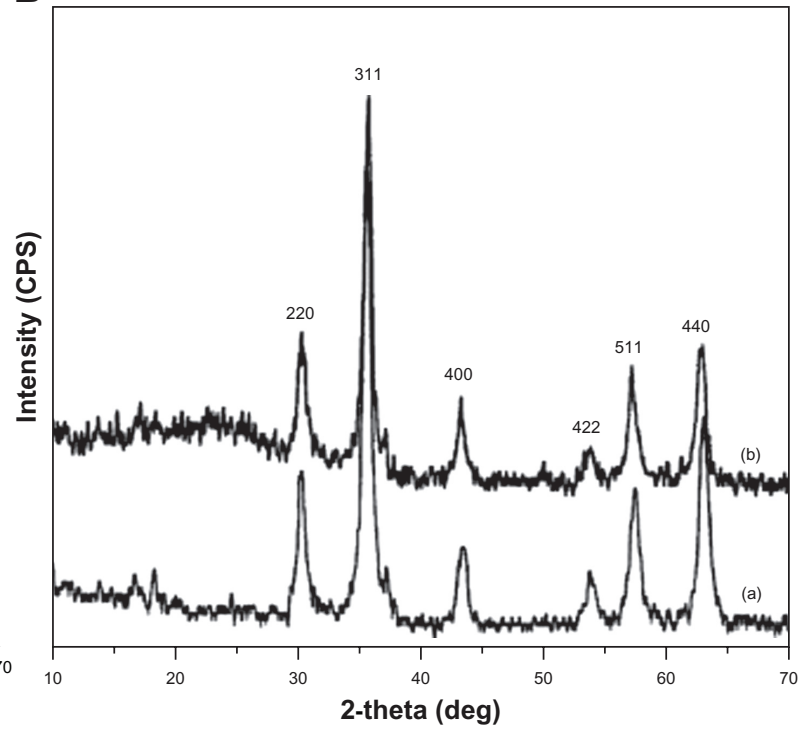

Figure 7 X-ray diffraction patterns of $(\mathbf{A})$ pure $\mathrm{Fe}_{3} \mathrm{O}_{4}$ nanoparticles and (B) PNIPAAm-MMA-grafted $\mathrm{Fe}_{3} \mathrm{O}_{4}$ nanoparticles. Abbreviations: PNIPAAm, poly ( $\mathrm{N}$-isopropylacrylamide); MAA, methyl methacrylic acid. 


\section{Characterization of $\mathrm{Fe}_{3} \mathrm{O}_{4}$ and PNIPAAm- MAA-coated $\mathrm{Fe}_{3} \mathrm{O}_{4}$ nanoparticles \\ $X$-ray diffraction patterns}

Figure 7 shows the X-ray diffraction patterns for the pure $\mathrm{Fe}_{3} \mathrm{O}_{4}$ and PNIPAAm-MAA-grafted $\mathrm{Fe}_{3} \mathrm{O}_{4}$ nanoparticles. It is apparent that the diffraction pattern of our $\mathrm{Fe}_{3} \mathrm{O}_{4}$ nanoparticles is close to the standard pattern for crystalline magnetite (Figure 7A). The characteristic diffraction peaks, marked by their respective indices (2 200$)$, ( $\left.\begin{array}{lll}3 & 1 & 1\end{array}\right)$, (4 $\left.\begin{array}{ll}4 & 0\end{array}\right),\left(\begin{array}{lll}4 & 2 & 2\end{array}\right),\left(\begin{array}{lll}5 & 1 & 1\end{array}\right)$, and (4 40 ) could be well indexed to the inverse cubic spinel structure of $\mathrm{Fe}_{3} \mathrm{O}_{4}$ (JCPDS card 85-1436), and were also observed for PNIPAAm-MAAgrafted $\mathrm{Fe}_{3} \mathrm{O}_{4}$ nanoparticles (Figure 7B). This indicates that modified graft polymerization on the surface of the $\mathrm{Fe}_{3} \mathrm{O}_{4}$ nanoparticles did not lead to any crystal phase change. The average crystalline size $\mathrm{D}$ was about $15 \mathrm{~nm}$, obtained from the Sherrer equation:

$$
\mathrm{D}=\mathrm{K} \lambda /(\beta \cos \theta)
$$

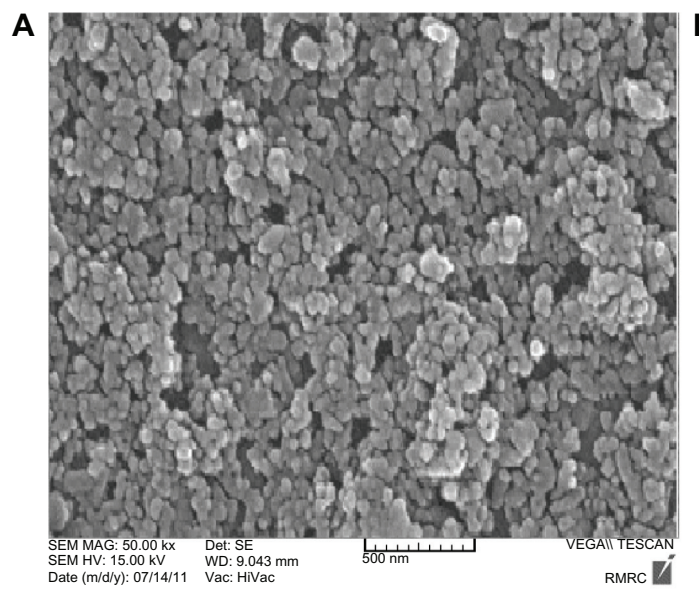

where $\mathrm{K}$ is a constant, $\lambda$ is the $\mathrm{X}$-ray wavelength, and $\beta$ is the peak width of half-maximum.

\section{Size, morphology, and core-shell structure of nanoparticles}

Scanning electron micrographs of pure $\mathrm{Fe}_{3} \mathrm{O}_{4}$ nanoparticles are shown in Figure 8A and $\mathrm{Fe}_{3} \mathrm{O}_{4}$ nanoparticles grafted by PNIPAAm-MAA are shown in Figure 8B. In Figure 8A, the nanoparticles were strongly aggregated, which was due to the nanosize of the $\mathrm{Fe}_{3} \mathrm{O}_{4}$, and were about $20-75 \mathrm{~nm}$ in size, according to the results of X-ray powder diffraction. After graft polymerization, the size of the particles increased to $60-100 \mathrm{~nm}$, and dispersion of the particles was greatly improved (Figure 8B), which can be explained by the electrostatic repulsion force and steric hindrance between the polymer chains on the surface of the $\mathrm{Fe}_{3} \mathrm{O}_{4}$ nanoparticles.

\section{Fourier transform infrared spectroscopy}

To evaluate the effect of graft polymerization, the homopolymers and unreacted monomers were extracted in ethanol to be

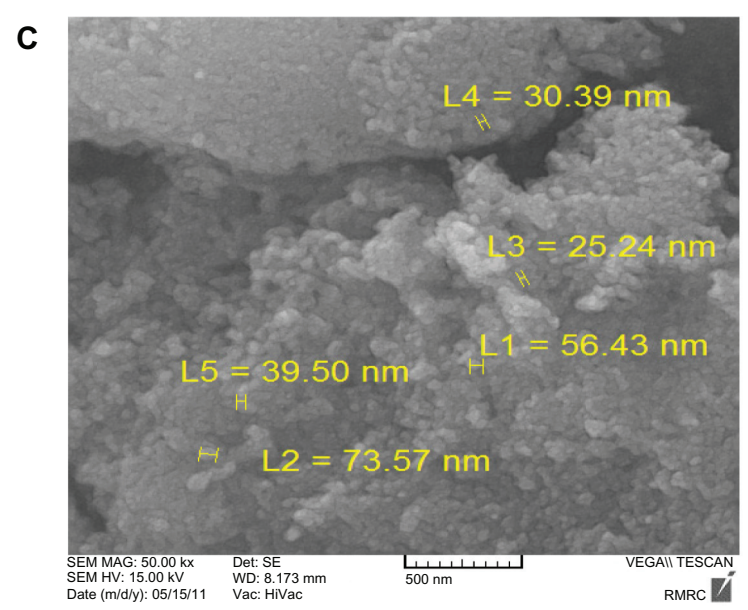

Figure 8 Scanning electron micrographs of $(\mathbf{A})$ pure $\mathrm{Fe}_{3} \mathrm{O}_{4}$ nanoparticles (B) $\mathrm{Fe}_{3} \mathrm{O}_{4}$ nanoparticles grafted by PNIPAAm-MMA, and (C) hydrodynamic sizes of PNIPAAmMAA-coated magnetic nanoparticles.

Abbreviations: PNIPAAm, poly (N-isopropylacrylamide); MAA, methyl methacrylic acid. 
separated from the grafted nanoparticles. Fourier transform infrared spectroscopy was used to show the structure of $\mathrm{Fe}_{3} \mathrm{O}_{4}$ (Figure 9A), vinyltriethoxysilane-modified $\mathrm{Fe}_{3} \mathrm{O}_{4}$ (Figure 9B), and PNIPAAm-MAA-grafted $\mathrm{Fe}_{3} \mathrm{O}_{4}$ (Figure 9C). From the infrared spectra shown in Figure 9, the absorption peaks at $568 \mathrm{~cm}^{-1}$ belonged to the stretching vibration mode of $\mathrm{Fe}-\mathrm{O}$ bonds in $\mathrm{Fe}_{3} \mathrm{O}_{4}$. Comparing the infrared spectra in Figure 9A and Figure 9B, vinyltriethoxysilane-modified $\mathrm{Fe}_{3} \mathrm{O}_{4}$ showed absorption peaks at 1603 and $1278 \mathrm{~cm}^{-1}$ attributable to the stretching vibrations of $\mathrm{C}=\mathrm{C}$ and the bending vibration of $\mathrm{Si}-\mathrm{C}$ bonds, a peak at $1411 \mathrm{~cm}^{-1}$ due to the bending vibration of the $=\mathrm{CH}_{2}$ group, and additional peaks centered at 1116 , 1041,962 , and $759 \mathrm{~cm}^{-1}$, most probably due to the symmetric and asymmetric stretching vibration of framework and terminal $\mathrm{Si}-\mathrm{O}$ - groups. All of these indicated the presence of vinyltriethoxysilane. They also indicated that the reactive groups had been introduced onto the surface of the magnetite. The absorption peaks of $\mathrm{C}=\mathrm{C}$ and $=\mathrm{CH}_{2}$ groups disappeared, and additional peaks at 1724, 1486, 1447 and $1387 \mathrm{~cm}^{-1}$ due to the stretching vibrations of $\mathrm{C}=\mathrm{O}$, the bending vibration of $-\mathrm{CH}_{2}-,-\mathrm{CH}-$, and $-\mathrm{CH}_{3}$ absorption peaks at 1147,906 , and $847 \mathrm{~cm}^{-1}$ belonged to the stretching vibration of the alkyl groups from NIPAAm. However, identification of a peak attributable to the stretching vibrations of $\mathrm{C}-\mathrm{N}$ (normally at about $1100 \mathrm{~cm}^{-1}$ ) was problematic due to other overlapping peaks, but the element analysis method demonstrated the presence of the $\mathrm{N}$ element of NIPAAm in PNIPAAmMAA-grafted $\mathrm{Fe}_{3} \mathrm{O}_{4}$ nanoparticles. Overall, these Fourier transform infrared spectra provided supportive evidence that the $-\mathrm{CH}=\mathrm{CH}_{2}$ group initiated polymerization of NIPAAm and MAA polymer chains, which were successfully grafted onto the $\mathrm{Fe}_{3} \mathrm{O}_{4}$ nanoparticle surface.

\section{Magnetism test}

The magnetic properties of the nanoparticles were analyzed using vibrating sample magnetometry at room temperature. Figure 10 shows the hysteresis loops for the samples. The saturation magnetization was found to be 34.5 and $17.6 \mathrm{emu} / \mathrm{g}$ for vinyltriethoxysilane-modified $\mathrm{Fe}_{3} \mathrm{O}_{4}$ and PNIPAAmMAA-grafted $\mathrm{Fe}_{3} \mathrm{O}_{4}$, respectively, which was less than for the pure $\mathrm{Fe}_{3} \mathrm{O}_{4}$ nanoparticles $(70.9 \mathrm{emu} / \mathrm{g})$. With its large saturation magnetization, the PNIPAAm-MAA-grafted $\mathrm{Fe}_{3} \mathrm{O}_{4}$ could be separated from the reaction medium rapidly and easily in a magnetic field. In addition, there was no hysteresis in the magnetization, with both remanence and coercivity being zero, suggesting that these magnetic nanoparticles were superparamagnetic. When the external magnetic field was removed, the magnetic nanoparticles could be well dispersed by gentle shaking. These magnetic properties are critical for applications in the biomedical and bioengineering fields.
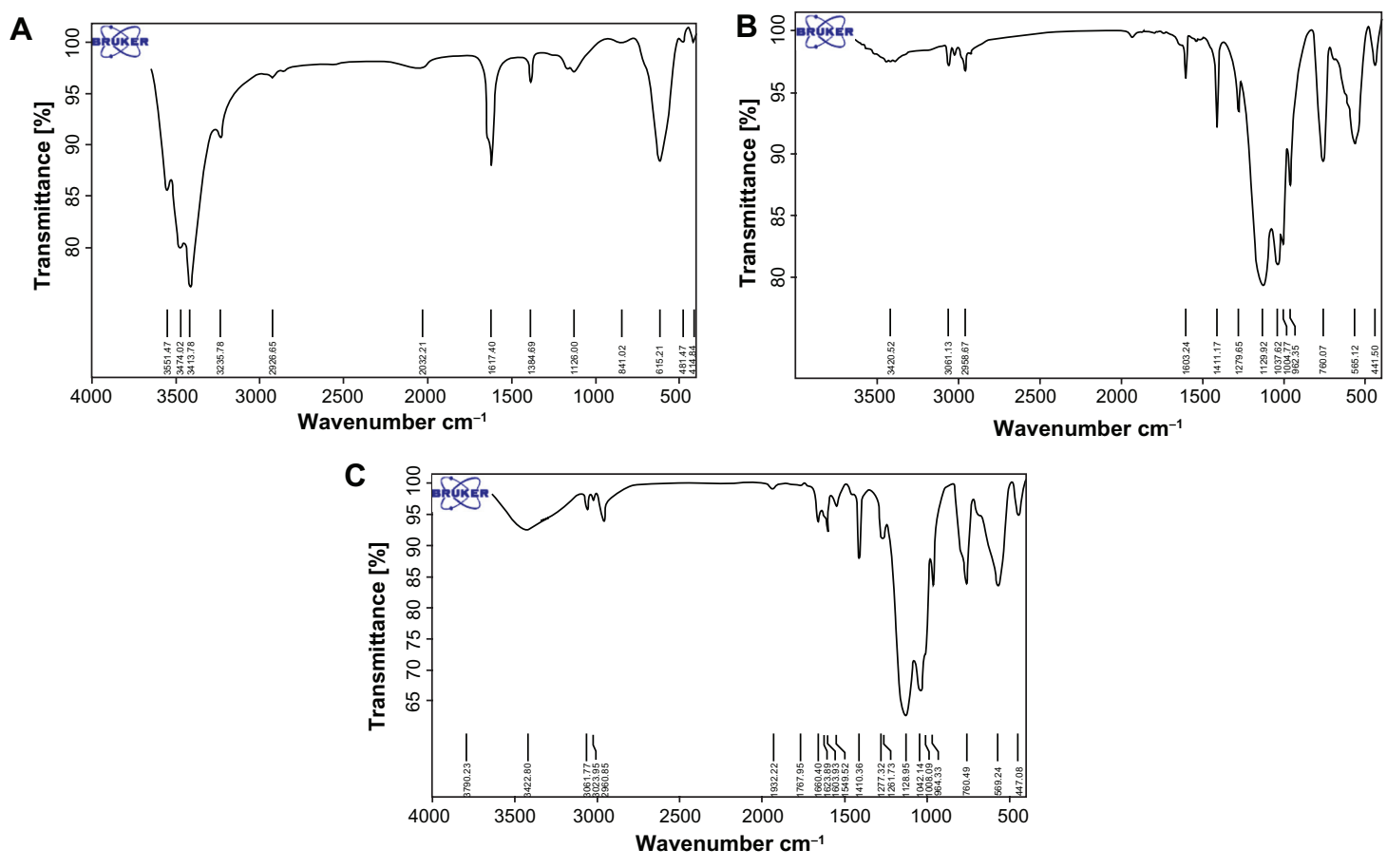

Figure 9 Fourier transform infrared spectra of $(\mathbf{A})$ pure $\mathrm{Fe}_{3} \mathrm{O}_{4}$ nanoparticles, (B) $\mathrm{Fe}_{3} \mathrm{O}_{4}$ nanoparticles modified by vinyltriethoxysilane, and (C) PNIPAAm-MMA-grafted $\mathrm{Fe}_{3} \mathrm{O}_{4}$ nanoparticles.

Abbreviations: PNIPAAm, poly (N-isopropylacrylamide); MAA, methyl methacrylic acid. 


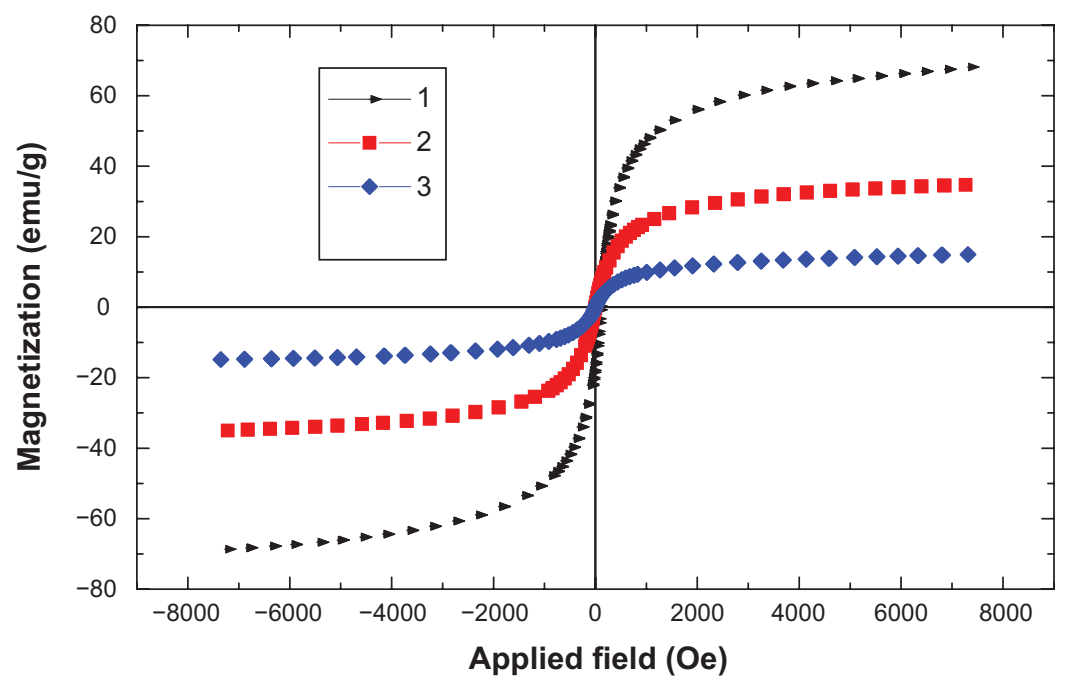

Figure 10 Magnetic behavior of magnetic nanoparticles $\left(\mathrm{Fe}_{3} \mathrm{O}_{4}, \mathrm{VTES}-\mathrm{Fe}_{3} \mathrm{O}_{4}\right.$, and $\left.\mathrm{VTES}-\mathrm{Fe}_{3} \mathrm{O}_{4}-\mathrm{PNIPAAm}-\mathrm{MAA}\right)$.

Abbreviations: PNIPAAm, poly (N-isopropylacrylamide); MAA, methyl methacrylic acid; VTES, vinyltriethoxysilane.

\section{Drug-loading efficiency}

Doxorubicin, an anticancer drug, was used for drug-loading and drug-release studies. In brief, $20 \mathrm{mg}$ of lyophilized nanoparticles and $5 \mathrm{mg}$ of doxorubicin were dispersed in phosphate buffer solution. The solution was stirred at $4^{\circ} \mathrm{C}$ for 3 days to allow doxorubicin to entrap within the nanoparticle network. This value was then compared with the total amount of doxorubicin to determine the doxorubicin loading efficiency of the nanoparticles. The amount of nonentrapped doxorubicin in the aqueous phase was determined using an ultraviolet-visible $2550\left(\lambda_{\text {ex }} 470 \mathrm{~nm}\right.$ and $\left.\lambda_{\text {em }} 585 \mathrm{~nm}\right)$ spectrometer (Shimadzu). This procedure enables analysis of doxorubicin solutions with removal of most interfering substances ${ }^{62}$ The entrapment efficiency of doxorubicin within the nanoparticles was calculated by the difference between the total amount used to prepare the nanoparticles and the amount of doxorubicin present in the aqueous phase. Loading efficiency was calculated according to the following formula:

Loading efficiency $\%=[($ Amount of loaded drug in $\mathrm{mg})$ /(Amount of added drug in $\mathrm{mg}$ )] $\times 100 \%$

\section{Drug release}

After 200 hours in phosphate buffer solution $(0.1 \mathrm{M}, \mathrm{pH}$ $7.4,5.8)$ at $37^{\circ} \mathrm{C}$ and $40^{\circ} \mathrm{C}$, the release behavior of the nanoparticles was studied. The percentage of cumulative release of doxorubicin at $40^{\circ} \mathrm{C}$ was significantly higher than at $37^{\circ} \mathrm{C}$ (Figure 11). The $\mathrm{pH}-$-responsive release profiles from the hybrid nanoparticles are shown in Figure 11 (pH 5.8 and 7.4). The release rate decreased with increasing
$\mathrm{pH}$ values. The $\mathrm{pKa}$ value of the amino group in doxorubicin was about 8.2. Thus, the electrostatic interaction existed in neutral surroundings and disappeared at acid surroundings. The $\mathrm{pH}$ of the tumor was 5.0-6.0, which is lower than the $\mathrm{pH}$ of normal tissue, so doxorubicin in the hybrid nanoparticles could be released at the tumor site.

\section{In vitro cytotoxicity study}

The MTT assay is an important method for evaluating the cytotoxicity of biomaterials in vitro. Using this assay, absorbance has a significant linear relationship with cell numbers. The corresponding optical images of cells are shown in Figure 12. In the current work, the MTT assay showed that doxorubicin-loaded PNIPAAm-MAA-coated magnetic nanoparticles have time-dependent but not dose-dependent cytotoxicity in an A549 lung cancer cell line

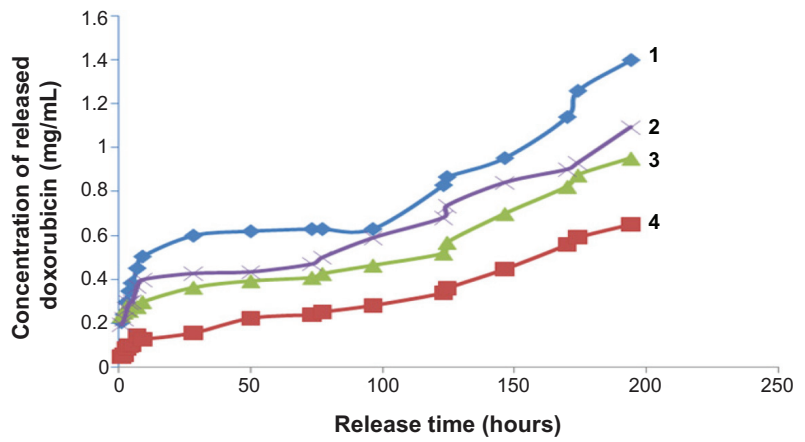

Figure I I Release profiles of doxorubicin from the hybrid nanoparticles at different $\mathrm{pH}$ values. Vertical axis shows: concentration of released doxorubicin $(\mathrm{mg} / \mathrm{mL})$ and horizontal axis shows release time (hours). (I) $\mathrm{pH} 5.8 \pm 0.0 \mathrm{I}$, temperature $40^{\circ} \mathrm{C} \pm 0.5^{\circ} \mathrm{C}$, (2) $\mathrm{pH} 5.8 \pm 0.0 \mathrm{I}$, temperature $37^{\circ} \mathrm{C} \pm 0.5^{\circ} \mathrm{C}$, (3) $\mathrm{pH} 7.4 \pm 0.0 \mathrm{I}$, temperature $40^{\circ} \mathrm{C} \pm 0.5^{\circ} \mathrm{C}$, (4) $\mathrm{pH} 7.4 \pm 0.0 \mathrm{l}$, temperature $37^{\circ} \mathrm{C} \pm 0.5^{\circ} \mathrm{C}$. 

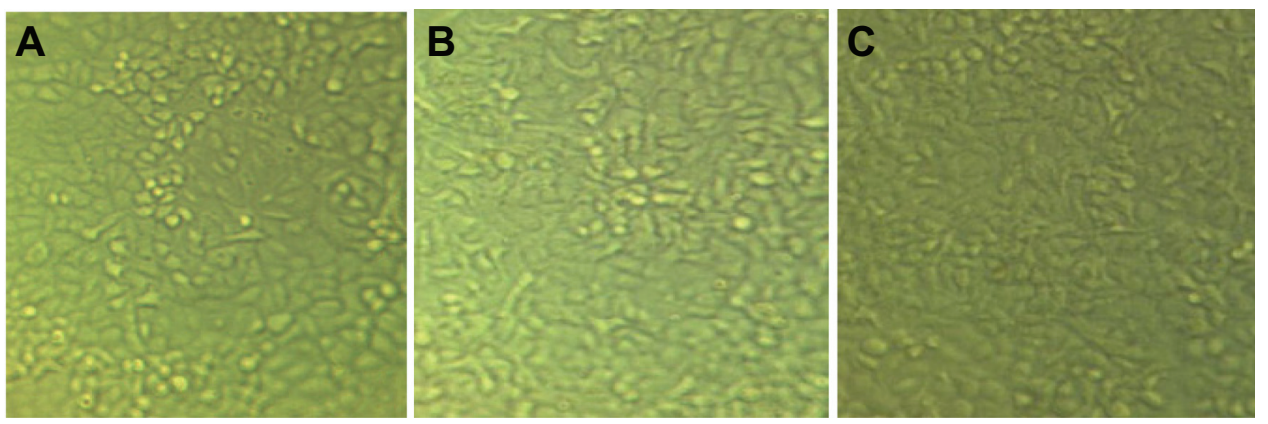

Figure 12 (A) Control cells, (B) doxorubicin-loaded PNIPAAm-MAA-coated magnetic nanoparticles, (C) pure doxorubicin. Morphological effect of doxorubicin-loaded PNIPAAm-MAA-coated magnetic nanoparticles in an A549 lung cancer cell line after 24 hours of treatment.

Abbreviations: PNIPAAm, poly ( $\mathrm{N}$-isopropylacrylamide); MAA, methyl methacrylic acid.

$\left(\mathrm{IC}_{50} 0.16-0.20 \mathrm{mg} / \mathrm{mL}\right)$. The MTT assay also showed that pure doxorubicin has dose-dependent but not time-dependent cytotoxicity in the A549 lung cancer cell line $\left(\mathrm{IC}_{50} 0.15-0.16 \mathrm{mg} / \mathrm{mL}\right)$. Therefore, there is a need for further study of doxorubicin-loaded PNIPAAm-MAAcoated magnetic nanoparticles in an A549 lung cancer cell line in the future. However, the results of our current work demonstrate that the $\mathrm{IC}_{50}$ values for doxorubicin-loaded PNIPAAm-MAA-coated magnetic nanoparticles and pure doxorubicin are about $0.16,0.20$, and $0.15 \mathrm{mg} / \mathrm{mL}$, respectively, in an A549 lung cancer cell line.

\section{Discussion}

In this work, we have characterized the in vitro behavior of PNIPAAm-MAA-coated magnetic nanoparticles for targeted and controlled drug delivery applications. The saturation magnetization was found to be 34.5 and $17.6 \mathrm{emu} / \mathrm{g}$ for vinyltriethoxysilane-modified $\mathrm{Fe}_{3} \mathrm{O}_{4}$ and PNIPAAmMAA-grafted $\mathrm{Fe}_{3} \mathrm{O}_{4}$, respectively, ie, less than for the pure $\mathrm{Fe}_{3} \mathrm{O}_{4}$ nanoparticles $(70.9 \mathrm{emu} / \mathrm{g})$ by vibrating sample magnetometry. This difference suggests that a large amount of silane and polymers were coated onto the surface of the $\mathrm{Fe}_{3} \mathrm{O}_{4}$ nanoparticles. Fourier transform infrared spectroscopy was used to show the structure of $\mathrm{Fe}_{3} \mathrm{O}_{4}$, vinyltriethoxysilanemodified $\mathrm{Fe}_{3} \mathrm{O}_{4}$, and PNIPAAm-MAA-grafted $\mathrm{Fe}_{3} \mathrm{O}_{4}$. The $\mathrm{X}$-ray powder diffraction data only showed peaks attributable to magnetite and revealed that modified and grafted polymerization onto the surface of $\mathrm{Fe}_{3} \mathrm{O}_{4}$ nanoparticles did not lead to crystal phase change. The size, morphology, and core-shell structure of the synthesized nanoparticles was analyzed by scanning electron microscopy. Close examination of a scanning electron microscopic image (inset in Figure 7) reveals the presence of magnetic nanoparticles (about $10 \mathrm{~nm}$ diameter) at the center with a PNIPAAm-MAA coating surrounding them. The size of the magnetic core was similar to earlier reported values for magnetic nanoparticles synthesized by similar methods. In comparison with PNIPAAm-coated magnetic nanoparticles, there was clearly less agglomeration of magnetic nanoparticles in the core. This might be a result of higher mixing capability due to utilization of a mechanical stirrer and the electrostatic charge repulsion from the carboxylic group of MAA in the PNIPAAm-MAA coating, which would further reduce the magnetic dipole interactions and promote stability. ${ }^{63}$ We believe that coating magnetic nanoparticles with a biocompatible polymer is necessary when high concentrations of magnetic nanoparticles are used. The drug-release study indicates that the PNIPAAm-MMA is a temperature-sensitive polymer, whereby at its lower critical solution temperature the nanoparticles go through a phase change to collapse and release more drug. After 200 hours, $60 \%$ of the bonded doxorubicin was released at $40^{\circ} \mathrm{C}$, whereas at $37^{\circ} \mathrm{C}$ about $43 \%$ was released. The release profile for doxorubicin over the first 30 minutes is also shown in Figure 11. After 30 minutes, the percentages of cumulative release of doxorubicin were only $0.046 \%$ at $37^{\circ} \mathrm{C}$, whereas at $40^{\circ} \mathrm{C}$ it was $2.4 \%$. The system is shown to release its payload over a short burst release period with changes in temperature. Since the measurement time was very short while the drug release predetermined time interval was significantly large, the influence of the returned medium on drug release during the measurement time is expected to be insignificant. The doxorubicin release profiles demonstrated that our nanoparticles were sensitive to temperature, with significantly higher release at $40^{\circ} \mathrm{C}$ than at $37^{\circ} \mathrm{C}$. The in vitro cytotoxicity test showed that the doxorubicin-loaded PNIPAAm-MAA-coated magnetic nanoparticles had no cytotoxicity and were biocompatible, which means that there is potential for biomedical application. ${ }^{64} \mathrm{Also}$, the $\mathrm{IC}_{50}$ of doxorubicin-loaded PNIPAAm-MAAcoated magnetic nanoparticles in an A549 lung cancer cell line showed that they are time-dependent. 


\section{Conclusion}

Superparamagnetic iron oxide nanoparticles were prepared via an improved chemical coprecipitation method, and magnetite $\left(\mathrm{Fe}_{3} \mathrm{O}_{4}\right)$ nanoparticles were then modified by vinyltriethoxysilicane and reactive groups were introduced onto the surface of the nanoparticles. NIPAAm and MAA were then grafted onto the surface of the modified $\mathrm{Fe}_{3} \mathrm{O}_{4}$ nanoparticles by surface-initiated radical polymerization. The results indicate that the polymer chains were effectively grafted onto the surface of the $\mathrm{Fe}_{3} \mathrm{O}_{4}$ nanoparticles. The functionalized particles remained dispersive and superparamagnetic. These particles were used for encapsulation of doxorubicin under mild conditions and could be used in drug delivery. The resulting particles were characterized by X-ray powder diffraction, scanning electron microscopy, Fourier transform infrared spectroscopy, and vibrating sample magnetometry. An in vitro cytotoxicity study demonstrated that the modified $\mathrm{Fe}_{3} \mathrm{O}_{4}$ nanoparticles had no cytotoxicity and were biocompatible. This study suggests that supercritical fluid technology is a promising technique to produce drug-polymer magnetic composite nanoparticles for the design of controlled drug-release systems. Our current work demonstrates that doxorubicin-loaded, modified $\mathrm{Fe}_{3} \mathrm{O}_{4}$ nanoparticles have a potent antigrowth effect in an A549 cancer cell line and inhibits cell growth in a timedependent manner. Therefore, these nanoparticles could be natural potent chemopreventive and chemotherapeutic agents for patients with lung cancer, and constituents of these nanoparticles may be appropriate candidates for drug development. Future work will include in vivo investigation of the targeting capability and effectiveness of these nanoparticles in the treatment of lung cancer. ${ }^{65,66}$

\section{Acknowledgments}

The authors are grateful for the financial support of the Iran National Science Foundation, Drug Applied Research Center Tabriz University of Medical Sciences, and the Department of Medicinal Chemistry at Tabriz University of Medical Sciences.

\section{Disclosure}

The authors report no conflicts of interest in this work.

\section{References}

1. Akbarzadeh A, Asgari D, Zarghami N, Mohammad R, Davaran S. Preparation and in vitro evaluation of doxorubicin-loaded $\mathrm{Fe}_{3} \mathrm{O}_{4}$ magnetic nanoparticles modified with biocompatible co-polymers. Int $\mathrm{J}$ Nanomedicine. In press.

2. Gref R, MinamitakeY, Peracchia MT, et al. Biodegradable long circulating polymeric nanospheres. Science. 1994;263:1600-1630.
3. Li Y, Pei Y, Zhang X, et al. PEGylated PLGA nanoparticles as protein carriers: synthesis, preparation and biodistribution in rats. $J$ Control Release. 2001;71:203-211.

4. Beletsi A, Panagi Z, Avgoustakis K. Biodistribution properties of nanoparticles based on mixtures of PLGA with PLGA-PEG diblock copolymers. Int J Pharm. 2005;298:233-241.

5. Birnbaum DT, Brannon-Peppas L. Microparticle drug delivery systems. In: Brown DM, editor. Drug Delivery Systems in Cancer Therapy. New York, NY: Humana Press; 2004.

6. Eatock MM, Schätzlain A, Kaye SB. Tumor vasculature as a target for anticancer therapy. Cancer Treat Rev. 2000;26:191-204.

7. Avgoustakis K, Beletsi A, Panagi Z, et al. Effect of copolymer composition on the physicochemical characteristics, in vitro stability, and biodistribution of PLGA-mPEG nanoparticles. Int J Pharm. 2003;259:115-127.

8. Jeong Y, Nah JW, Lee HC, et al. Adriamycin release from flower-type polymeric micelles based on star-block copolymer composed of poly ( $\gamma$-benzyl L-glutamate) as the hydrophobic part and poly(ethylene oxide) as the hydrophilic part. Int J Pharm. 1999;188:49-58.

9. Jeong B, Bae YH, Kim SW. Drug release from biodegradable injectable thermosensitive hydrogel of PEG-PLGA-PEG triblock copolymer. J Control Release. 2000;63:155-163.

10. Kwon GS, Naito M, Yokoyama M, et al. Physical entrapment of adriamycin in AB block copolymer micelle. Pharm Res. 1995;12:192-195.

11. Mitra S, Gaur U, Ghosh PC, et al. Tumor targeted delivery of encapsulated dextran-doxorubicin conjugate using chitosane nanoparticles as carrier. J Control Release. 2001;74:317-323.

12. Na K, Lee ES, Bae YH. Adriamycin loaded pullulan acetate/sulfonamide conjugate nanoparticles responding to tumor $\mathrm{pH}$ : $\mathrm{pH}$-dependent cell interaction, internalization and cytotoxicity. J Control Release. 2003;87:3-13.

13. Orive G, Hernández RM, Gasc AR, et al. Micro and nano drug delivery systems in cancer therapy. Cancer Ther. 2005;3:131-138.

14. Panyam J, Labhasetwar V. Biodegradable nanoparticles for drug and gene delivery to cells and tissue. Adv Drug Deliv Rev. 2003;55:329-347.

15. Banerjee SS, Chen DH. Magnetic nanoparticles grafted with cyclodextrin for hydrophobic drug delivery. Chem Mater. 2007;19: 6345-6349.

16. Jain TK, Reddy MK, Morales MA, Leslie-Pelecky DL, Labhasetwar V. Biodistribution, clearance, and biocompatibility of iron oxide magnetic nanoparticles in rats. Mol Pharm. 2008;5:316-327.

17. Jain TK, Richey J, Strand M, Leslie-Pelecky DL, Flask CA, Labhasetwar V. Magnetic nanoparticles with dual functional properties: drug delivery and magnetic resonance imaging. Biomaterials. 2008;29:4012-4021.

18. Lai JJ, Hoffman JM, Ebara M, et al. Dual magnetic-/temperatureresponsive nanoparticles for microfluidic separations and assays. Langmuir. 2007;23:7385-7391.

19. Hu SH, Liu TY, Liu DM, Chen SY. Nano-ferrosponges for controlled drug release. J Control Release. 2007;121:181-189.

20. Liu TY, Hu SH, Liu KH, Liu DM, Chen SY. Study on controlled drug permeation of magnetic-sensitive ferrogels: effect of $\mathrm{Fe}_{3} \mathrm{O}_{4}$ and PVA. J Control Release. 2008;126:228-236.

21. Müller-Schulte D, Schmitz-Rode T. Thermosensitive magnetic polymer particles as contactless controllable drug carriers. J Magn Magn Mater. 2006;302:267-271.

22. Rahimi M, Yousef M, Cheng Y, Meletis EI, Eberhart RC, Nguyen K. Formulation and characterization of a covalently coated magnetic nanogel. J Nanosci Nanotechnol. 2010;10(9):6072-6081.

23. Arias JL, Ruiz MA, Gallardo V, Delgado AV. Tegafur loading and release properties of magnetite/poly (alkylcyanoacrylate) (core/shell) nanoparticles. J Control Release. 2008;125:50-58.

24. Gupta AK, Curtis AS. Surface modified superparamagnetic nanoparticles for drug delivery: interaction studies with human fibroblasts in culture. J Mater Sci Mater Med. 2004;15:493-496.

25. Zhang J, Misra RD. Magnetic drug-targeting carrier encapsulated with thermosensitive smart polymer: core-shell nanoparticle carrier and drug release response. Acta Biomater. 2007;3:838-850. 
26. Zhang JL, Srivastava RS, Misra RD. Core-shell magnetite nanoparticles surface encapsulated with smart stimuli-responsive polymer: synthesis, characterization, and lower critical solution temperature (LCST) of viable drug-targeting delivery system. Langmuir. 2007;23:6342-6351.

27. Zintchenko A, Ogris M, Wagner E. Temperature dependent geneexpression induced by PNIPAM-based copolymers: potential of hyperthermia in gene transfer. Bioconjug Chem. 2006;17:766-772.

28. Chilkoti A, Dreher MR, Meyer DE, Raucher D. Targeted drug delivery by thermally responsive polymers. Adv Drug Deliv Rev. 2002;54:613-630.

29. Meyer DE, Shin BC, Kong GA, Dewhirst MW, Chilkoti A. Drug targeting using thermally responsive polymers and local hyperthermia. J Control Release. 2001;74:213-224.

30. Hu Z, Huang G. A new route to crystalline hydrogels, guided by a phase diagram. Angew Chem Int Ed Engl. 2003;42:4799-4802.

31. Rahimi M, Kilaru S, Hajj S, et al. Synthesis and characterization of thermo-sensitive nanoparticles for drug delivery applications. J Biomed Nanotechnol. 2008;4:1-9.

32. Peppas LB, Blanchette JO. Nanoparticle and targeted systems for cancer therapy. Adv Drug Deliv Rev. 2004;56:1649-1659.

33. Ren J, Jia MH, Ren TB, Yuan WZ, Tan QG. Preparation and characterization of PNIPAAm-b-PLA/ $\mathrm{Fe}_{3} \mathrm{O}_{4}$ thermo-responsive and magnetic composite micelles. Mater Lett. 2008;62:4425-4427.

34. Yang Yong, Yongxiao Bai, Yanfeng Li, Lei Lin, Yanjun Cui, Chungu Xia. Preparation and application of polymer-grafted magnetic nanoparticles for lipase immobilization. J Magn Magn Mater. 2008;320:2350-2355

35. Rahimi M, Wadajkar A, Subramanian K, et al. In vitro evaluation of novel polymer-coated magnetic nanoparticles for controlled drug delivery. Nanomedicine. 2010;6:672-680.

36. Wu CL, He H, Gao HJ, et al. Synthesis of $\mathrm{Fe}_{3} \mathrm{O}_{4} @ \mathrm{SiO}_{2} @$ polymer nanoparticles for controlled drug release. Science China Chemistry. 2010;53:514-518.

37. Nattama S, Rahimi M, Wadajkar AS, et al. Characterization of polymer coated magnetic nanoparticles for targeted treatment of cancer. Engineering in Medicine and Biology Workshop. Dallas, TX: IEEE; 2007: 35-38. doi:10.1109/EMBSW.2007.4454167.

38. Butoescu N, Jordan O, Burdet P, et al. Dexamethasone-containing biodegradable superparamagnetic microparticles for intra-articular administration: physicochemical and magnetic properties, in vitro and in vivo drug release. Eur J Pharm Biopharm. 2009;72:529-538.

39. Butoescu N, Seemayer CA, Foti M, Jordan O, Doelker E. Dexamethasone-containing PLGA superparamagnetic microparticles as carriers for the local treatment of arthritis. Biomaterials. 2009;30:1772-1780.

40. Perez JM, O’Loughin T, Simeone FJ, Weissleder R, Josephson L. DNAbased magnetic nanoparticle assembly acts as a magnetic relaxation nanoswitch allowing screening of DNA-cleaving agents. J Am Chem Soc. 2002;124:2856-2857.

41. Kinsella JM, Ivanisevic A. Enzymatic clipping of DNA wires coated with magnetic nanoparticles. J Am Chem Soc. 2005;127:3276-3277.

42. Xu CJ, Xu KM, Gu HW, et al. Dopamine as a robust anchor to immobilize functional molecules on the iron oxide shell of magnetic nanoparticles. J Am Chem Soc. 2004;126:9938-9939.

43. Kim J, Lee JE, Lee J, et al. Magnetic fluorescent delivery vehicle using uniform mesoporous silica spheres embedded with monodispersed magnetic and semiconductor nanocrystals. J Am Chem Soc. 2006;128:688-689.

44. Lu AH, Salabas EL, Schüth F. Magnetic nanoparticles: synthesis, protection, functionalization, and application. Angew Chem Int Ed Engl. 2007;46:1222-1244.

45. Yang XQ, Chen YH, Yuan RX, et al. Folate-encoded and $\mathrm{Fe}_{3} \mathrm{O}_{4}$ loaded polymeric micelles for dual targeting of cancer cells. Polymer. 2008;48:3477-3485.

46. Chang Y, Bai YP, Teng B, Li ZL. A new drug carrier: magnetite nanoparticles coated with amphiphilic block copolymer. Chin Sci Bull. 2009;54:1190-1196.
47. Hu FX, Neoh KG, Kang ET. Synthesis of folic acid functionalized PLLA-b-PPEGMA nanoparticles for cancer cell targeting. Macromol Rapid Commun. 2009;30:609-614.

48. Guo M, Yan Y, Zhang HK, et al. Magnetic and pH-responsive nanocarriers with multilayer core-shell architecture for anticancer drug delivery. J Mater Chem. 2008;18:5104-5112.

49. Lu J, Ma S, Sun JY, et al. Manganese ferrite nanoparticle micellar nanocomposites as MRI contrast agent for liver imaging. Biomaterials. 2009;30:2919-2928.

50. Thünemann AF, Schütt D, Kaufner L, Pison U, Möhwald H. Maghemite nanoparticles protectively coated with poly (ethyleneimine) and poly(ethylene oxide)-block-poly(glutamic acid). Langmuir. 2006;22:2351-2357.

51. Zintchenko A, Ogris M, Wagner E. Temperature dependent gene expression induced by PNIPAM-based copolymers: potential of hyperthermia in gene transfer. Bioconjug Chem. 2006;17:766-772.

52. Meyer DE, Shin BC, Kong GA, Dewhirst MW, Chilkoti A. Drug targeting using thermally responsive polymers and local hyperthermia. J Control Release. 2001;74:213-224.

53. Chen FH, Gao Q, Ni JZ. The grafting and release behavior of doxorubincin from $\mathrm{Fe}_{3} \mathrm{O}_{4} @ \mathrm{SiO}_{2}$ core-shell structure nanoparticles via an acid cleaving amide bond: the potential for magnetic targeting drug delivery. Nanotechnology. 2008;19:165103

54. Santra S, Tapec R, Theodoropoulou N, Dobson J, Hebard A, Tan WH. Synthesis and characterization of silica-coated iron oxide nanoparticles in microemulsion: the effect of nonionic surfactants. Langmuir. 2001;17:2900-2906.

55. Kaushik A, Khan R, Solanki PR, et al. Iron oxide nanoparticleschitosan composite based glucose biosensor. Biosens Bioelectron. 2008;24:676-683.

56. Reynolds AR, Moghimi SM, Hodivala-Dilk K. Nanoparticle-mediated gene delivery to tumor vasculature. Trends Mol Med. 2003;9:2-4.

57. WU ChengLin, HE Huan, GAO HongJun, et al. Synthesis of $\mathrm{Fe}_{3} \mathrm{O}_{4} @ \mathrm{SiO}_{2} @$ polymer nanoparticles for controlled drug release. 2010;53:514-518.

58. Yang J, Lee $\mathrm{CH}, \mathrm{Ko} \mathrm{HJ}$, et al. Multifunctional magneto-polymeric nanohybrids for targeted detection and synergistic therapeutic effects on breast cancer. Angew Chem Int Ed Engl. 2007;46:8836-8839.

59. Yu MK, Jeong YY, Park J, et al. Drug-loaded superparamagnetic iron oxide nanoparticles for combined cancer imaging and therapy in vivo. Angew Chem Int Ed Engl. 2008;47:5362-5365.

60. Carmichael J, DeGraff WG, Gazdar AF, Minna JD, Mitchell JB. Evaluation of a tetrazolium-based semiautomated colorimetric assay: assessment of chemosensitivity testing. Cancer Res. 47:936-942.

61. Mohammad P, Nosratollah Z, Mohammad R, Abbas A, Javad R. The inhibitory effect of Curcuma longa extract on telomerase activity in A549 lung cancer cell line. African Journal of Biotechnology. 2010;9:912-919.

62. Savva M, Duda E, Huang L. A genetically modified recombinant tumor necrosis factor-alpha conjugated to the distal terminals of liposomal surface grafted poly-ethyleneglycol chains. Int J Pharm. 1999; 184:45-51

63. Arbab AS, Bashaw LA, Miller BR, et al. Characterization of biophysical and metabolic properties of cells labeled with superparamagnetic iron oxide nanoparticles and transfection agent for cellular MR imaging. Radiology. 2003;229:838-846.

64. Mahmoudi M, Sant S, Wang B, Laurent S, Sen T. Superparamagnetic iron oxide nanoparticles (SPIONs): development, surface modification and applications in chemotherapy. Adv Drug Deliv Rev. 2011;63:24-46.

65. Davaran S, Entezami AA. A review on application of polymers in new drug delivery systems. Iranian Polymer Journal. 1994;6(4): 273-289.

66. Davaran S, Entezami AA. Synthesis and hydrolysis of modified poly vinyl alcohols containing ibuprofen pendent groups. Iranian Polymer Journal. 1996;5(3):188-191. 


\section{Publish your work in this journal}

Nanotechnology, Science and Applications is an international, peerreviewed, open access journal that focuses on the science of nanotechnology in a wide range of industrial and academic applications. It is characterized by the rapid reporting across all sectors, including engineering, optics, bio-medicine, cosmetics, textiles, resource sustainability and science. Applied research into nano-materials, particles, nanostructures and fabrication, diagnostics and analytics, drug delivery and toxicology constitute the primary direction of the journal. The manuscript management system is completely online and includes a very quick and fair peer-review system, which is all easy to use.

Submit your manuscript here: http://www.dovepress.com/nanotechnology-science-and-applications-journal 